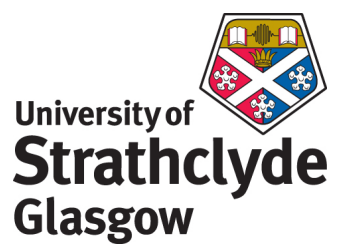

Forbes, Joan and McCartney, Elspeth (2010) Social capital theory: a cross-cutting analytic for teacher/therapist work in integrating children's services? Child Language Teaching and Therapy . ISSN 0265-6590

http://strathprints.strath.ac.uk/26749/

Strathprints is designed to allow users to access the research output of the University of Strathclyde. Copyright $(C$ and Moral Rights for the papers on this site are retained by the individual authors and/or other copyright owners. You may not engage in further distribution of the material for any profitmaking activities or any commercial gain. You may freely distribute both the url (http://strathprints.strath.ac.uk) and the content of this paper for research or study, educational, or not-for-profit purposes without prior permission or charge. You may freely distribute the url (http://strathprints.strath.ac.uk) of the Strathprints website.

Any correspondence concerning this service should be sent to The Strathprints Administrator: eprints@cis.strath.ac.uk 


\title{
Social capital theory: A cross-cutting analytic for teacher/therapist work in integrating children's services?
}

Child Language Teaching and Therapy http://clt.sagepub.com

(S)AGE

\author{
Joan Forbes and Elspeth McCartney \\ University of Aberdeen
}

\begin{abstract}
Reviewing relevant policy, this article argues that the current 'integration interlude' is concerned with reformation of work relations to create new forms of 'social capital'. The conceptual framework of social capital has been used by government policy-makers and academic researchers to examine different types, configurations and qualities of relationships, including professional relations, and how these may function as resources. Focusing on the co-work of teachers and speech and language therapists, this analysis introduces social capital as a means of understanding the impact of integrating children's services on professional practitioner groups and across agencies. Social capital theory is compared to alternative theoretical perspectives such as systems and discourse theories and explored as an analytic offering a multi-level typology and conceptual framework for understanding the effects of policy and governance on interprofessional working and relationships.A previous application of social capital theory in a literature review is introduced and analysed, and instances of the additionality provided by a social capital analysis is offered. The article concludes that amongst the effects of current policy to re-design children's services are the reconstruction of professionals' knowledge/s and practices, so it is essential that such policy processes that have complex and far-reaching effects are transparent and coherent. It is also important that new social capital relations in children's services are produced by groups representative of all involved, importantly including those practitioner groups charged in policy to work differently together in future integrated services.
\end{abstract}

\section{Keywords}

children's services integration, social capital theory, interprofessional, interagency, professional knowledges, professional identities

\section{Corresponding author:}

Elspeth McCartney, Speech and Language Therapy Division, Educational and Professional Studies Department, University of Strathclyde, 76 Southbrae Drive, Glasgow, GI3 IPP, UK

Email: e.mccartney@strath.ac.uk 


\section{Introduction}

Work relations within children's services are currently being remodelled as part of what may be termed an 'integration interlude' (Smith, 2008). That is, current children's public services policy is driving the design and implementation of new more integrated social capital relations amongst the professions involved. This article explores earlier inter-professional collaboration policy and more recent commitments to children's service integration, focusing on the changing work practices between teachers and speech and language therapists (hereafter, therapists) in Scottish schools, as an example of a long-established inter-professional relationship (McCartney, Ellis and Boyle, 2006) that crosses traditional public sector boundaries.

The major policy document Getting it Right for Every Child (Scottish Executive, 2005) proposes a unified approach to children's services in Scotland, replacing previously dyadic (one-toone) professional inter-relationships. An important effect of this policy 'step-change' is to alter the relations of social capital created and distributed between professions involved in the delivery of children's services.

Policies with parallel intent are also reconfiguring services to children in other UK countries and across the Anglophone world in an example of 'traveling [sic] policy' (Lindblad and Popkewitz, 2004) and 'policy borrowing' (Butt and Gunter, 2009). A similar reform agenda in the United States underpins the No Child Left Behind Act of 2001 (US Congress, 2002). In England a programme of reform of children's services has been instituted driven by the Children Act 2004 (Brown, 2009), usually referred to as the Every Child Matters agenda (DfES, 2004; DfES, 2005 and see Pugh, 2009). In Northern Ireland a strategy for children and young people and an integrated service agenda has been developed around an Extended Schools initiative, implemented in the context of a substantial review of education and public administration (DE, 2005; OFMDFM, 2006 and see Moran, Abbott and O'Connor, 2009); in Wales see A Fair Future for our Children (The Welsh Assembly Government, 2005); and in Eire: Giving Children an Even Break (Department of Education and Science (IE), 2001).

Previous policies had not ignored the need for co-professional working. In Scotland for example, the Manual of Good Practice in Special Educational Needs (SOEID, 1998) enjoined practitioner flexibility and 'co-ordinated inter-agency approaches' (34) with shared approaches to identification and assessment; strategic policies; effective planning and resource allocation; and structures and procedures for monitoring and evaluating services. Such discourses of interagency working were based on principles and practices of coordination and collaboration, and sought to augment or replace previous professional values of autonomy, knowledge and responsibility (Forbes, 2001). Such a focus on work between agencies, the 'inter'-regnum (Hartley's 2009 term), did result in improved coordination and collaboration between identified professional groups and agencies (such as speech and language therapists and teachers, education and health) (Forbes, 2006). However, more recent policy and legislative drivers towards integration of children's services - the 'integration interlude' - will have farther-reaching effects, as new types and qualities of relations among all practitioners in the children's workforce are forged.

It is this shift of policy focus - from the promotion of collaboration between practitioners from different professional groups working together in schools to a commitment to integrate children's services - that this article explores, asking questions relating to governance and policy study; the practitioner knowledges needed, available and lacking for practice in the new integrated contexts; and the reconfigurations of practice needed to respond to identified gaps and/or overlaps in available practitioner knowledge bases. The concept of social capital, 'an increasingly familiar one in the social sciences' (Field, 2005: 5, and see Field, 2003), is introduced to analyse such questions, 
and a rationale offered for its potential fruitfulness as a tool to map and analyse the types and qualities of working relations.

\section{The new policy agenda: Children's services integration}

Since the early years of the new millennium Scottish policy for children and young people has moved from adapting schools to form the focus of joint children's services to a wider integration agenda. The previous commitment had been 'that all schools will have adopted the new [now integrated] community schools approach by 2007' (Scottish Executive, 2002: 10). Community or integrated schools (ICS) were intended to act as the 'hub' - and catalyst - for local school and community change, including acting as the hub or nexus for integrated provision, management and delivery of services to introduce 'a more holistic approach to [children's] needs' (Scottish Office, 1998: 4-5). Recent Scottish Government policy revises this commitment to community schools as the hub for children's service transformation, relocating the space of integration from the school to children's services:

A Partnership for a Better Scotland made the commitment that by 2007 every school in Scotland would be an Integrated Community School. In effect the ICS initiative has developed and the commitment has been overtaken by the wider integration agenda. It no longer makes sense to think of schools separately from other agencies. We would now say that: by 2007 every school in Scotland will participate in delivering Integrated Children's Services. (SEED, 2006: unpaginated)

One effect of not 'thinking of schools separately from other agencies' is that a policy focus on how one specific school/agency partnership, such as co-working between speech-language therapists (SLT) and education staff, operates in practice has been subsumed into a more general concern with reconstructing (inter)professionalism and interagency relations in the context of integrated services (Forbes, 2009). Initiatives focus on 'driving forward better integrated services for ... children' (Scottish Executive, 2002: 10), restructuring schools and other services. These initiatives are high profile and centrally funded through, for example, a 'Changing Children's Services Fund' (p. 10), and for local authorities a component of a National Priorities Action Fund. These documents contain important messages for all practitioners and professional groups enjoined to accept and act upon policy integrating children's services.

The move away from ICSs reflects the fact that integrating children's services at school level did not occur as smoothly as envisaged. Her Majesty's Inspectorate of Education's (HMIe, 2004: 28) report of the development of ICS concluded that:

The ICS initiative has not been fully successful in its aim of establishing a new over-arching vision and framework for the delivery of education and other children's services using schools as the hub.

HMIe attributed this limited success in establishing new frameworks for children's services delivery within school sites to difficulties in 'engaging the commitment of all relevant practitioners' (p. 28) and with the 'often limited awareness ... among professionals in other agencies' (p. 28) (i.e. non-school, non-education agencies).

As outlined above, policy has now moved on from thinking of schools separately from the other agencies involved in delivering integrated children's services. However, there is still some way to go towards integration in practice. The most recent report by HMIe (2009), which is based on inspection and review data from 2005-08, identifies a number of issues that remain to be addressed in relation to child service partnerships. It notes: 
Individuals, establishments and services cannot on their own deliver what is required in today's demanding context. Priorities are:

- Strengthening partnerships across sectors and services in ways which create a unified learning and support system $[\ldots]$

- Ensuring that education plays its full part in taking forward the GiRFEC [Getting it Right for Every Child] approach, actively seeking and embedding the behaviours which will sustain effective partnership working. (p. 96)

Research is urgently needed to explore the quality and materiality of types of practitioner engagement and relations, and to produce a fine-grained examination of the concerns that HMIe (2009) discerned relating to 'not fully successful interprofessional ties' [emphasis added], that is, professionals' social capital. At the micro-level of the individual and the knowledge and skills which individual practitioners bring to co-practice relations, integration of children's services is now having effects for children's workforce modernization, restructuring and remodelling (Butt and Gunter, 2009). For children's service integration to succeed in ways that school 'hubs' did not, considerations of 'children's workforce futures' will need to take more careful account of the subject disciplinary and practice-specific knowledges (Gibbons et al., 1994) which practitioners currently hold and with which they identify. Current workforce remodelling deliberations necessitate a careful rethinking and reconstitution of the micro-level professional knowledge bases, values and meso-level practices (Forbes, 2009) now needed within macro-level governance and policy aiming to re-design children's services. The present article is analytical in nature with a focus on the working out of some of these issues. It introduces and discusses the application of social capital theory as a potentially fruitful theoretical framework to examine such new constitutions and relations.

\section{Previous theoretical orientations to teacher/SLT co-working and what social capital theory might offer}

Martin (2008) outlines two key paradigms of interprofessional interagency working, systems theory (McCartney et al., 1998; McCartney, 1999a; 1999b) and identity and power approaches (Forbes, 2003, 2001). Following Engeström (see, for example, Engeström, 2001, 2007), she offers a sociocultural approach as an alternative. The present authors suggest that each of these paradigms has limits. Systems approaches are useful in contrasting separate services, such as schools and SLT agencies, but may tend towards normative accounts that focus on organizational goals and activities and under-specify the relational realities experienced by staff. They thus fail to uncover important perspectives in the interstices between and amongst different children's services' systems. Power and identity approaches take critical account of discourses and practices not only at the level of interinstitutional and inter-professional practice, but also at a level that may be applied, for example, to analyse the dimensions of power that operate at the level of governance and policy and to examine the micro-level knowledges that individuals hold and use. Concerned with issues of power, conflict, resistance and 'alternative views of organisational goals' (Field, 2009: 22), such approaches avoid prescription of how practices 'should be conducted' (p. 22). However, there is a risk that power and identity approaches, particularly when combined with discourse or narrative theory method, may fail to uncover important dimensions of practitioners' and professional groups' relations of power, knowledge, trust and other identifications. Finally, the present authors would argue that the new paradigm offered by a socio-cultural theory approach risks analyses, and so understandings, that are methodologically confined primarily to the 'cultural-social-institutional plane' (Howard, 2008: 26, citing Bonilla-Silva, 2001, 2003). An important effect of all such institutionally-focused analyses 
may be that influences on children's services external to the institution - for example those at the intra-individual level such as practitioners' personal stocks and deployments of knowledge and trust - are consistently under-theorized, under-conceptualized and under-analysed.

\section{Social capital theory: Additionality to systems, identity/power and socio-cultural theories}

The present article therefore outlines an alternative approach to research into professionals' relations in integrated working in schools and children's services, drawing on social capital theory. This includes studies that have emerged from:

- the Applied Educational Research Scheme (AERS);

- Schools and Social Capital Network (SSCN) in Scotland (http://www.aers.org.uk);

- a 2006-07 Economic and Social Research Council (ESRC) research seminar series (entitled 'Service integration in schools - research and policy discourses, practices and future prospects'; see Forbes and Watson, 2009a); and

- a current ESRC seminar series, entitled 'The effects of human and cultural capital for interprofessional social capital: Exploring professional identities, knowledges and learning for inter-practitioner relationships and interprofessional practice in schools and children's services' (see Forbes and Watson, 2009b; 2009c).

Further, a sub-strand of an AERS-SSCN literature review activity is introduced and analysed. First, however, to aid the analysis of social capital that follows, a mapping is offered of how social capital theory might be applied at the levels of governance, practice and individual practitioners.

As outlined above, the overarching theoretical framework here is that of social capital (Bourdieu, 1986; Coleman, 1988; Putnam, 1993, 2000). The World Bank (1999) refers to social capital as the 'glue' that holds together social interactions, relationships and institutions. Social capital theory pays attention to the 'social' and to power/resources, to provide an account of how power and resources are built up and operate in and through social connections and relations. In Putnam's (2000) classic study, Bowling alone: The collapse and revival of American Community, it was used to examine connectedness and civic engagement in American associational and community life. It offers the possibility of moves between the levels of governance and policy, the institutional plane, and the individual or personal plane. Thus, it conceptually develops both systems theory and power and identity theories by offering improved understandings of (inter)professional governancepractice-knowledge bases.

Conceptualized as a multi-level matrix (Halpern, 2005), social capital theory offers a methodological approach that moves between the macro, meso and micro multi-systemic levels, i.e. the governance and policy, institutional, and individual or personal planes. Social capital theory should thus conceptually enhance systems and power and identity approaches, and the understandings of (inter)professional governance-practice-knowledge base which those approaches in isolation offered. Social capital frameworks also offer the possibility of a more fruitful understanding of trans-professional identities and power relations than a socio-cultural approach limited to the cultural-social-institutional plane.

Previous examinations and explorations of professional linkages and relations attest the conceptual and analytical insights offered by social capital theory (see, for example, an analysis of the role of social capital in Scottish education and social care policy in Arshad et al., 2007; an analysis of different forms of professionalism in Kennedy et al., 2007; and an account of an 

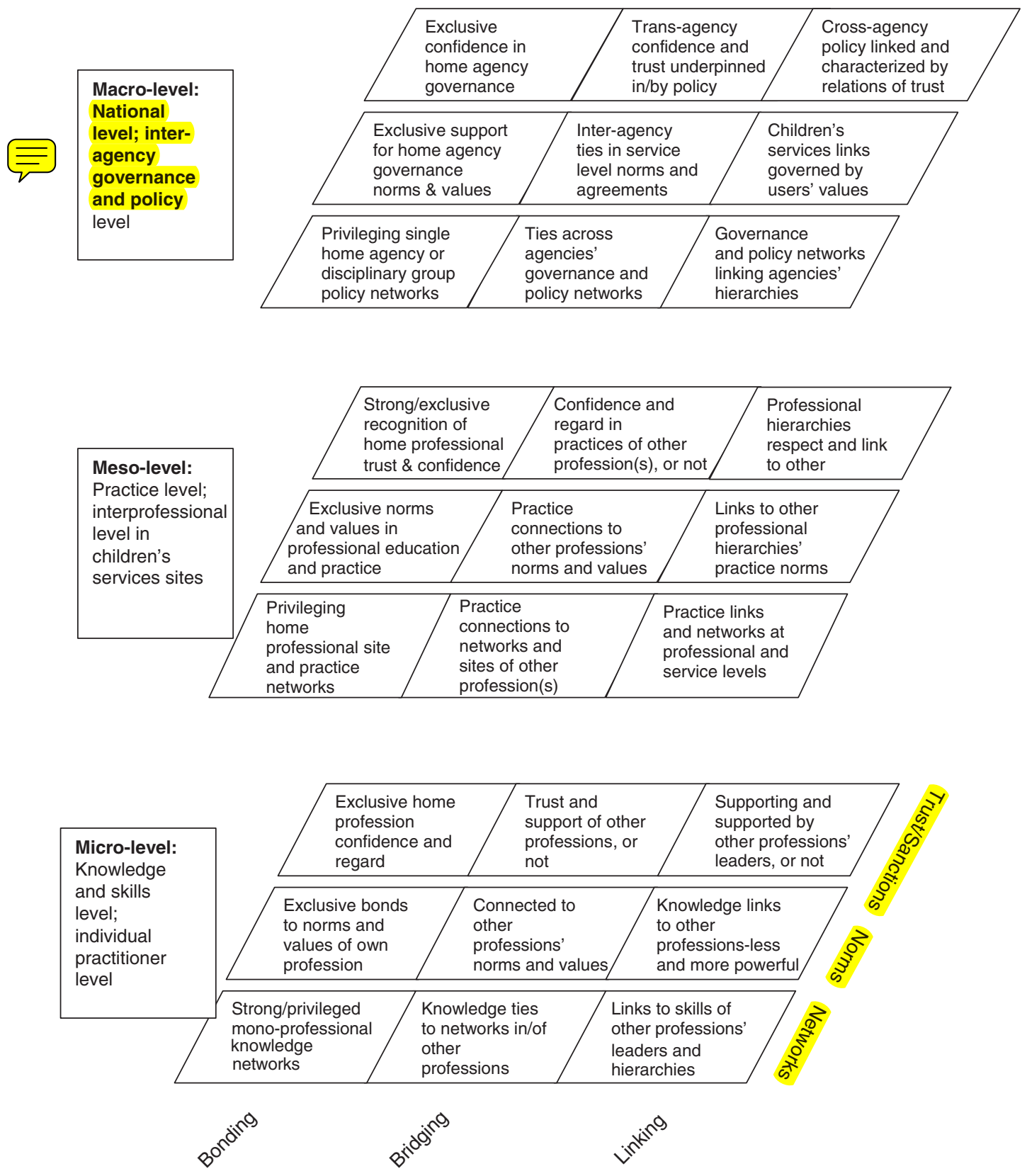

Figure I. A conceptual map of interprofessional social capital Source: adapted from Halpern, 2005

inter and trans-professional literature review in Ozga et al., 2008). Whilst other 'capital' constructs such as cultural capital (Bourdieu, 1977, 1990, 1998) and human capital (Halpern, 2005; Swartz, 1997) offer conceptual and analytical power in relation to the formation of a professional, 
the conceptual framework of social capital provides specific purchase on the forms and functioning of practitioner interrelationships. Thus, the framework is examined here as a potentially productive new theoretical paradigm in the remodelled workforce context of children's services integration relations, presenting a powerful way of analysing and understanding integrated children's service work between practitioner groups and across agencies. It facilitates better understanding of the effects of policy and governance on inter-professional working and copractice relationships; and of the knowledge and skills identifications that practitioners hold and bring to those work relations.

The research of Putnam $(2000,2002)$ into the economic and social benefits of association and social network formation provides a theoretical rationale for the recent raft of integrated children's services policy initiatives in Scotland and in other UK countries (Forbes, 2007). Following Putnam, Halpern (2005: 10) emphasizes that social capital also has a range of important outcomes related to economic growth, performance and efficacy. For Halpern social capital is concerned with the ways in which people are connected with one another through particular social structures and networks, including professional association. It focuses on the quality of social norms, customs and ties that define people and groups, promote trust, provide individuals with shared understandings of how to behave, and operate to keep people together. As mapped and illustrated with specific examples of teacher/therapist connections in the multi-level Figure 1, Halpern (2005: 10) identifies the three basic components of most forms of social capital, including the form of interest here - work-based social capital - in the following terms:

They consist of a network; a cluster of norms, values and expectancies that are shared by group members; and sanctions - punishments and rewards - that help to maintain the norms and network.

Putnam (2000: 22) describes sub-types of social capital connections: bonding (exclusive of others not in the group) and bridging (inclusive of non-group others) noting:

bonding and/or bridging: The former may be more inward looking and have a tendency to reinforce exclusive identities and homogenous groups. The latter may be more outward-looking and encompass people across different social divides.

A model of social capital may then be developed along the two axes of (1) components of social capital and (2) sub-types of social capital, allowing an analysis of relations and connections at three levels:

- the inter-personal level, taking account of intra-personal human capital in the form of particular knowledge and skills;

- the inter-professional service level; and

- the governance and policy level.

As indicated above, the examination of professional/practitioner ties in schools and children's services' sites constitutes the focus of this analysis. Using a conceptual map that envisages the intersections of different practitioners' and practitioner groups' (here teachers' and therapists') bonding and bridging connections with those professionals' norms (of values, expectancies and of practice) and sanctions (punishments and rewards) allows practitioner service-level connections to be identified and analysed. 


\section{A summary of key social capital concepts}

The analyses below draw on the key social capital terms and concepts introduced and illustrated above:

- the axis of networks, norms and trust and reciprocity; and

- the axis of sub-types of social capital: bonding (can be exclusive), bridging (is inclusive of other groups) and linking (connects individuals to different levels in other organizational and institutional power hierarchies).

Together, these two axes constitute a multi-level matrix of social capital relations, which offers the possibility of mapping the intersections of the key terms and sub-types of social capital at macro (policy and governance level constituents), meso (the level of practice and of the operation of power relations in practice relationships across children's services), and micro (the knowledge/s and skills needed by individual practitioners) levels.

\section{Applying social capital theory to explore macro-level issues of children's services policy and governance}

This section draws on an inter/transprofessionalism sub-strand of the AERS-SSCN literature review on 'Redesigning professionalism and enabling professionals to use, recognize and develop social capital'. A full account is available in Forbes in Allan et al., 2009. This review was contextualized in the (rapidly changing) Scottish children's services policy context and the analytical framework of social capital outlined above.

A social capital framing of macro-level relations is outlined using a single question concerning social capital issues that emerged from the progressive focusing occurring at each stage of the literature review (Forbes, 2009). Then, serving heuristically, a social capital analytical framework is applied in a review of McCartney's (1999) systems theory approach.

\section{The macro-level: Integrated agency governance and policy}

The junctions of networks with bonding, bridging and linking sub-types might be constituted as follows. Relevant agency governance and policy privileges, institutes and supports:

- bonding: strong work relations with/within own home agency and subject disciplinary area (e.g. linguistics);

- bridging: good inter-practitioner inter-agency work relations underpinned by appropriate mixes of human capital (academic qualifications, knowledge bases and skills);

- linking: good work relations across relevant institutions' (subject disciplinary, professions, agencies) hierarchies at all levels (practitioner, service, policy and governance), underpinned by the interprofessional inter-agency structures and forums needed to institute and support change effectively towards integration in children's public services.

This framework allows consideration of governance and policy discourse and statements, if these are to take account of practitioners' social capital/relations, and also the values, disciplinary subject-specific and practice knowledge/s, skills and work practices that characterize and underlie practitioners' stocks of social capital, i.e. particular configurations of work relations. 
An early text that applies systems theory to analyse teacher/therapist collaboration/integrating services focuses on barriers and obstacles. It identifies difficulties and limitations to joint working between education and health 'systems' based on forms of organization and professionality that are unsuited, on the evidence offered, to the purpose of co-working or of integrating practices (McCartney, 1999a). Pre-dating the introduction of more differentiated terminology for cross cutting relationships (e.g. Brown and White, 2006; McCartney, 2009), this text uses 'collaboration' for work relations between practitioners within health and education systems (but see pp. 31-34).

The text was written just as public sector services were moving from a position where co-working was encouraged to one where it was becoming mandated. The overarching theory was therefore linked to the then taken-for-granted conceptualization of health and education as two separate organizations or systems. That 'systems', 'whole systems' and 'organizations' are social constructions, and so open to change is not addressed, and is perhaps unlikely to be examined due to the ontological and epistemological assumptions underlying systems theory in general. Further, the systems model used by McCartney (1999a) deliberately separated structures from functions, since collaborating practitioners operate within established structural parameters (pp. 19-20, and see also McCartney et al., 1998). This particular systems model will tend to reify organizational structures.

Indeed, McCartney considered the fact that health and education were separate and different organizational systems to be the 'overriding issue' affecting co-working (p. 1):

These two professions work in separate, large, impressive organisations, each with its own expectations and practices - SLTs in the health service, teachers in education. These organizational systems ... are very different in the ways in which they go about [service delivery]. Differences between the systems can mean that it is not particularly easy to collaborate. (p. 1)

There is also an explicit assertion that 'the fact that collaboration takes place across two major public services creates significant barriers to collaboration' (p. 5) and that 'the prevailing system is heavily loaded against multi-professional co-operation' (p. 25). Such relations between teachers and therapists, education and health, as 'take place [are] a tribute to the determination and realism of professionals in the field' (p. 1). This led to discussion of 'bridging the divide' and how it is individual practitioners (usually SLTs) who find ways to coordinate on an 'ad-hoc basis'; for example:

it is the SLT profession that has made the most change, by giving up its 'expert who extracts' role and moving into the classroom ... Education ... may have to move a little further in making the SLTs feel entirely welcome. Education as a system is somewhat unused to dealing with professionals who expect to be partners who collaborate rather than employees to be controlled. (pp. 172-73)

However, McCartney also argues:

that functional, structural and systems environment barriers to communication present particular difficulties that must be overcome, but that collaboration at a process level (where decisions are made for individual children) is fairly well developed. (p. 5)

and that the book:

reflects a point in time when it seems possible to look forward to collaborative working becoming the normal and expected means by which education and SLT services are delivered to school children. (p. 172) 
And as outlined above, since 1999 the idea of separate health and education systems has altered both in Scottish Government policy and legislation and, in wider UK children's services, governance and policy. A shift in focus from identifying (and perhaps explaining or indeed excusing) on-going obstacles to collaboration and integration is therefore needed, and an analytic capable of focusing on practitioner and agency relations, and examining closely their types (bonding within, bridging across, hierarchically linking) and their materiality (networks; practitioner norms, values and knowledge bases; trust and reciprocity).

The application of a social capital theory analytic reveals a number of policy and governancelevel issues that underlie the positions assumed and argued for in the above systems theory approach:

- In what terms does current policy specify what constitutes legitimate forms of 'collaborative' network relations between SLTs/teachers and health/education?

- Should the ways in which specific relational work resources function, and to whose benefit, be unpacked and examined?

- What are the new norms of collaborative (or integrative) practice between SLTs/teachers, and/or amongst other children's service practitioners, as articulated in policy?

- What values and knowledges are assumed within/by those norms?

- Do work relations in practice, albeit not in governance and policy statements, remain about education gaining 'control' and access to a staff resource, or is there evidence of an emergent professional culture that values the other as equal practitioners (Slee, cited in Allan, 2004: 18)?

- In the current 'integrative' moment what kinds of 'welcome', acceptance and relations of trust, regard and reciprocity are legitimated in policy and governance regimes?

- Do children's services policy and governance need to explicitly support practitioners to establish trans-professional relationships based on a 'non-othering' relational ethic?

\section{What does social capital theory add?}

Recent integrative policy seems to have been driven by questions of the best use of economic capital and issues concerning employing scarce resources in children's public services within a prevailing 'market' regime (Hartley, 2009) that privileges 'effectiveness' (Nixon et al., 2001). Applying social capital theory would ensure that future policy would be driven by hard questions concerning underlying norms and values and the professional networks and relations of trust and reciprocity that such policies institute. The application of social capital theory would re-insert a proper and timely concern with the social into policy reformulations and systems restructurings (Halpern, 2005).

Researchers in health, social services and education are seeking a common theoretical and analytical language to explore common big issues and hard questions in relation to subject disciplinary and professional groups involved in transforming children's public services. Social capital theory grasps the types and materiality of relational connections, and highlights points of disjuncture in connections, at the levels of policy, practice and formation. Social capital analyses can also identify policy imperatives that work against the integration agenda. For example, a social capital analysis of the raft of policy across agencies involved in delivering children's public services might avoid incoherency and disjuncture in practice, and so improve joined-up conceptualizations of the knowledges and skills required for the professional development of future children's public service practitioners. 


\section{Conclusions and suggestions regarding future applications}

The article argues that the current 'integration interlude' is concerned in important ways with the reformation of work relations and the formation of new and different social capital norms and relations at all levels and across all planes. In this change, practitioners need a methodological approach such as that provided by social capital theory with which to grasp, unpack and understand the (sometimes rapidly and intensively) changing inter-professional and inter-agency relations they are experiencing, the changing inter-professional and inter-agency relations with which they are being asked to identify, and in which they are being asked to invest their trust.

The empirical task of mapping the inter-professional interstices or 'knotting points' enables points where collaborative ties need to be remade for the benefit of practitioners and service users to be identified and analysed. Such applications of social capital theory are analytically fruitful in identifying the explicit knowledge/skills-mixes and the particular ties-mix needed for specified inter-professional roles and remits within children's services settings. Each practitioner will hold and will need to draw upon a different mix of social capital networks, norms and trust to undertake specific practices within their co-work. It is important to ensure that the overall balance of social capital types (bonding, bridging and linking) is correct, and that it is appropriate to what people do and need to do.

It is crucial that policy conceptualizations and processes - which send out messages instituting new norms and values that reconstruct underlying professional identities and knowledge/s, and which fundamentally affect practice relations amongst professional groups and agencies in complex and far-reaching ways - should be transparent and coherent. Further, all practitioners involved require an adequate conceptual toolkit with which to question and fully understand the values, principles and practices that underlie and flow from policy concerning changed professional relations.

With wider and fuller practitioner understanding of the need to take seriously the question of professional relationships, future policy constructs and messages to redesign children's services should - and could - be opened-up and be produced through 'community engagement' (Nixon et al., 2001) by inclusive and democratic groups that are representative of all involved (Sachs, 2003). Critically, control of the form that social capital resources and networks take needs to include the practitioners who will be charged by policy to understand, identify, and operate in new work relations.

Finally, drawing on Halpern (2005: 4) 'social capital should be valued for its potential to facilitate individual and community action.' As suggested above, enhanced professional social capital constituted and instituted through practitioner involvement - holds the promise and potential to promote better collective action on shared professional problems. Strengthened social capital across children's services that institutes more open representation and access to the authority and legitimization of decision-makers, sponsors and resources may be put to work to the benefit of all practitioners involved and so, most critically, produce improved public services for the benefit of children and young people.

\section{References}

Allan J (2004) Working together to support inclusion. Education in The North 12: 14-20.

Allan J, Ozga J, and Smyth G (eds) Social capital, professionalism and diversity. Rotterdam: Sense.

Arshad R, Forbes J, and Catts R (2007) The role of social capital in Scottish education policy. Scottish Educational Review 39(2): 127-37.

Bonilla-Silva E (2001) White supremacy and racism in the post civil rights era. Boulder, CO: Rienner. 
Bonilla-Silva E (2003) Racism without racists: Colour-blind racism and the persistence of racial inequality in the United States. Boulder, CO: Rowman and Littlefield.

Bourdieu P (1977) Cultural reproduction and social reproduction. In: Karrabul J and Halsey AH (eds) Power and ideology in education. New York: Oxford University Press, 487-511.

Bourdieu P (1986) The forms of capital. In: Richardson JG (ed.) Handbook of theory and research for the sociology of education. New York: Greenwood, 241-58.

Bourdieu P (1990) The logic of practice. Cambridge: Polity Press.

Bourdieu P (1998) Practical reason. Cambridge: Polity Press.

Brown D (2009) Leadership and capacity in the public sector: Integrated children's services and schools. In: Forbes J and Watson C (eds) Service integration in schools: Research and policy discourses, practices and future prospects. Rotterdam: Sense, 109-25.

Brown K and White K (2006) Exploring the evidence base for integrated children's services. Edinburgh: Scottish Executive Education Department (SEED).

Butt G and Gunter H (2009) Modernising and remodelling schools: Are there 'global solutions' to transforming the school workforce? In: Forbes J and Watson C (eds) Service integration in schools: Research and policy discourses, practices and future prospects. Rotterdam: Sense, 145-56.

Coleman J (1988) Social capital in the creation of human capital. American Journal of Sociology 94 (supplement): S95-S120.

Department of Education (DE) (Northern Ireland) (2005) Draft supplementary guidance to support the impact of SENDO on the code of practice on the identification and assessment of special educational needs. Bangor: Department of Education

Department of Education and Science (IE) Social Inclusion Unit (2001) Giving children an even break by tackling disadvantage in primary schools. Dublin: Department of Education and Science. Retrieved from: http:// www.education.ie/home/home.jsp?pcategory=17216\&ecategory=34287\&language=EN (August 2010).

Department for Education and Skills (DfES) (2004) Every child matters: Change for children. London: Department for Education and Skills.

Department for Education and Skills (DfES) (2005) Children's workforce strategy. London: Department for Education and Skills.

Engeström Y (2001) Expansive learning at work: Towards an activity theoretical reconceptualisation. Journal of Education and Work 14(1): 133-56.

Engeström Y (2007) Putting activity theory to work: The change laboratory as an application of double simulation. In: Daniels H, Cole M, and Wertsch JV (eds) Cambridge companion to Vygotsky. Cambridge: Cambridge University Press, 363-82.

Field J (2003) Social capital. Abingdon: Routledge.

Field J (2005) Social capital and lifelong learning. Bristol: The Policy Press.

Field J (2009) A social capital toolkit for schools? Organisational perspectives on current social capital research. In: Allan J, Ozga J, and Smyth G (eds) Social capital, professionalism and diversity. Rotterdam: Sense, 21-35.

Forbes J (2001) Teacher/therapist collaboration policy: An analysis. Child Language Teaching and Therapy 17(3): 195-205.

Forbes J (2003) Grappling with collaboration: Would opening up the research 'base' help? British Journal of Special Education 30(3): 150-55.

Forbes J (2006) For social justice and inclusion: Engaging with the other. Journal of Research in Special Educational Needs 6(2): 99-107.

Forbes J (ed.) (2007) How service integration is operating in practice in the Scotland, Northern Ireland and England and Wales policy contexts: ESRC seminar 2 proceedings, research paper 15. Aberdeen: University of Aberdeen. 
Forbes J (2009) Redesigning professional knowledge using social capital. In: Allan J, Ozga J, and Smyth G (eds) Social capital, professionalism and diversity. Rotterdam: Sense, 91-106.

Forbes J and Watson C (eds) (2009a) Service integration in schools: Research and policy discourses, practices and future prospects. Rotterdam: Sense.

Forbes J and Watson C (eds) (2009b) Research into professional identities: Theorising social and institutional identities: ESRC seminar 1 proceedings, research paper 18. Aberdeen: University of Aberdeen.

Forbes J and Watson C (eds) (2009c) Exploring subject disciplinary and practice specific knowledges and learning for interprofessional practice: ESRC seminars 2 and 3 proceedings, research paper 19. Aberdeen: University of Aberdeen.

Gibbons M, Limoges C, Nowotny H, Schwartzman S, Scott P, and Trow M (1994) The new production of knowledge. London: Sage.

Halpern D (2005) Social capital. Cambridge: Polity.

Hartley D (2009) Education policy and the 'inter'-regnum. In: Forbes J and Watson C (eds) Service integration in schools: Research and policy discourses, practices and future prospects. Rotterdam: Sense, 127-40.

HM Inspectorate of Education (HMIe) (2009) Improving Scottish Education: A report by HMIE on inspection and review 2005-2008. Livingston: HM Inspectorate of Education.

HM Inspectorate of Education (HMIe) (2004) The sum of its parts? The development of integrated community schools in Scotland. Edinburgh: HM Inspectorate of Education.

Howard A (2008) Learning privilege: Lessons of power and identity in affluent schooling. Abingdon: Routledge.

Kennedy A, Christie D, Forbes J, Fraser C, MacDonald A, Menter I, Paton G, and Reid L (2007) Changing teachers, changing Scotland? Scottish Educational Review 39(1): 60-71.

Lindblad S and Popkewitz TS (2004) Educational restructuring: International perspectives on traveling policies. Greenwich: Information Age Publishing.

Martin D (2008) A new paradigm to inform inter-professional learning for integrating speech and language provision into secondary schools: A socio-activity theory approach. Child Language Teaching and Therapy 24(2): 173-92.

McCartney E (ed.) (1999a) Speech/language therapists and teachers working together. London: Whurr.

McCartney E (1999b) Barriers to collaboration: an analysis of systemic barriers to collaboration between teachers and speech and language therapists. International Journal of Language and Communication Disorders 34(4): 431-40.

McCartney E (2009) Joining up working: Terms, types and tensions. In Forbes J and Watson C (eds) Service integration in schools: Research and policy discourses, practices and future prospects. Rotterdam: Sense, 23-36.

McCartney E, MacKay G, Cheseldine S, and McCool S (1998) The development of a systems analysis approach to small-scale educational evaluation. Educational Review 50(1): 65-73.

McCartney E, Ellis S, and Boyle J (2006) Support your local co-op: Developing co-operative approaches to speech and language therapists and teachers supporting children with language impairment. In: Forbes J (ed.) Children's services integration in Scottish schools: Research seminar proceedings, research paper 13. Aberdeen: University of Aberdeen, 7-23.

Moran A, Abbott L, and O'Connor U (2009) Communicating, coordinating and connecting: Integrated service provision in Northern Ireland. In: Forbes J and Watson C (eds) Service integration in schools: Research and policy discourses, practices and future prospects. Rotterdam: Sense, 65-76.

Nixon J, Allan J, and Mannion G (2001) Educational renewal as democratic practice: 'new' community schooling in Scotland. International Journal of Inclusive Education 5(4): 353-65.

Office of the First Minister and Deputy First Minister (OFMDFM) (2006) Our children and young people: Our pledge: A ten year strategy for children and young people in Northern Ireland, 2006-2016. Belfast: OFMDFM. 
Ozga J, Hulme M, and McGonigal J (2008) Teacher professionalism and social capital: Applied educational research scheme briefing, paper 2. Edinburgh: AERS Consortium.

Pugh G (2009) Every child matters: The implications for service integration in England. In: Forbes J and Watson C (eds) Service integration in schools: Research and policy discourses, practices and future prospects. Rotterdam: Sense, 77-92.

Putnam RD (1993) The prosperous community: Social capital and public life. The American Prospect 13(Spring): $35-42$.

Putnam RD (2000) Bowling alone: The collapse and revival of American community. New York, NY: Simon and Schuster.

Putnam RD (ed.) (2002) Democracies in flux: The evolution of social capital in contemporary society. Oxford: Oxford University Press.

Sachs J (2003) The activist teaching profession. Buckingham: Open University Press.

Scottish Executive (2002) Closing the opportunity gap: Scottish Budget for 2003-2006. Edinburgh: Scottish Executive.

Scottish Executive (2005) Getting it right for every child: Proposals for action. Edinburgh: Scottish Executive.

Scottish Executive Education Department (SEED) (2006) Improving outcomes for children and young people: The role of schools in delivering integrated children's services. Edinburgh: SEED.

Scottish Office Education Department (SOEID) (1998) A manual of good practice in special educational needs. Edinburgh: SOEID.

Smith M (2008) Neither social nor working: Changing social work identities in Scotland. Unpublished paper presented at ESRC seminar. Research into professional identities: Theorising social and institutional identities. University of Aberdeen, 29-30 May 2008.

Swartz D (1997) Culture and power: The sociology of Pierre Bourdieu. Chicago, IL: The University of Chicago Press.

United States 107th Congress (2002) An act to close the achievement gap with accountability, flexibility and choice, so that no child is left behind. This title may be cited as the 'No child left behind act of 2001'. Public Law 107-10. Washington: US Congress. Retrieved from: http://www2.ed.gov/policy/elsec/leg/ esea02/107-110.pdf (August 2010).

Welsh Assembly Government (2005) A fair future for our children. Cardiff: The Welsh Assembly Government. Retrieved from: http://wales.gov.uk/dsjlg/publications/childrenyoung/fairfuture/strategye?lang=en (Jully 2010). 